\title{
Digital Media and Disciplinarity
}

\author{
Jonathan Sterne \\ Department of Art History and Communication Studies, McGill University, Montreal, Quebec, \\ Canada
}

This article asks two related questions: Is digital media studies a discipline, and should scholars within the field desire to move toward disciplinarity? Drawing on the writings of Michel Foucualt and Pierre Bourdieu, as well as several Anglo-American cultural studies of disciplinarity, the essay argues that digital media studies has not yet constituted a truly novel scholarly discourse. Because of that, our reasons for disciplinizing - to the extent that it is possible to choose to become a discipline-would be largely strategic. Given that the field is already successfully reproducing itself, the symbolic benefits of becoming a discipline are relatively limited, and such a move would also have significant intellectual costs.

Keywords cultural studies, digital media studies, disciplinarity, discipline, Internet studies, Michel Foucault, new media studies, Pierre Bourdieu, sociology of knowledge

In their introduction to a volume on disciplinarity in cultural studies, Cary Nelson and Dilip Parameshwar Gaonkar relate the story of an English professor, Nuel Pharr Davis, who published an "institutional and interpersonal cultural history" of the work at the Los Alamos laboratories entitled Lawrence and Oppenheimer (1968). The book took years to write and required extensive research trips and wide reading in physics. When it was published, it received broad critical acclaim. But when Davis approached his senior colleagues about using the book as grounds for promotion from associate to full professor of English, they balked. It had nothing to do with English literature, after all. So Davis remained an asso-

Received 26 February 2004; accepted 4 December 2004.

Many thanks to Carrie Rentschler, Lisa Nakamura, Nancy Baym, and three anonymous reviewers for their comments on earlier drafts of this essay.

Address correspondence to Jonathan Sterne, Department of Art History and Communication Studies, McGill University, 853 Sherbrooke St. W., Montreal, QC Canada H3A 2T6. E-mail: jonathan.sterne@ mcgill.ca; web site http://sterneworks.org ciate professor. Years later, when asked why he wrote the book, Davis replied, "Those who have facility with language, including English professors, have a responsibility to record and analyze the great events of their time for the benefit of future generations" (Nelson \& Gaonkar, 1996, p. 2). Nelson and Gaonkar (1996) take this as an allegory about the difference between those who see intellectuals as having a broad responsibility to a public and those who believe academics' primary intellectual responsibility is to their home discipline. Thirty years later, the battle lines are drawn differently, but every faculty must still wrestle with questions of disciplinarity and interdisciplinarity in its curriculum, hiring, and tenuring practices, and every scholar must wrestle with questions of disciplinarity and interdisciplinarity as $\mathrm{we}^{1}$ seek to educate ourselves, build our research, and navigate our careers. Many people could call up stories of academics who were denied access to jobs or access to tenure because their work did not fit within an extant disciplinary paradigm. The stakes of Davis's tale are relatively limited, since promotion to full professor is a relatively small matter in comparison. But if we look at Davis's pronouncement, at least one important thing has changed: It is now much more common to receive recognition for interdisciplinary work, as the rise of digital media studies $^{2}$ exemplifies.

Davis's ideas are in fact very old. In one of the founding documents of modern social thought, Giabattista Vico (1984) argued that it is precisely because people have the power to change the world that we are charged with the task of changing. For the benefit of future generations, indeed! So let us now expand Davis's very reasonable account of intellectual responsibility to something more interdisciplinary: Those who have facility with language, numbers, ideas, archives, interviewing, and interpreting have a responsibility to record and analyze the great events of their time for the benefit of future generations.

Countless authors have argued that the rise of digital media - the Internet, computers, video games, compact discs, DVDs - marks one of the great events of our time. On this matter, I am actually agnostic: To make a claim 
for a shift we are currently experiencing implies that we have more certain foreknowledge of developments in technology, ecology, culture, and geopolitics than we actually do. Transformations in the near future could, theoretically, dwarf the so-called digital revolution in significance. Conversely, the advent of digital media could also be historically significant in ways we cannot yet even fathom. Historical assessment is difficult enough when the historian has distance from his or her object. But it is certainly fair to say that many people believe the proliferation of digital media is one of the great events of our time.

Therein lies the difference between now and 30 years ago. While Davis was effectively punished for his venture from disciplinarity to chronicle a great event, the analysis of momentous changes in contemporary media has been a concern across the human sciences. Contributions to the analysis of digital media come from so-called "traditional" disciplines-such as economics or anthropology—and interdisciplinary fields like women's studies or cognitive science. Regardless of whether one thinks digital media studies is or should be a discipline, there is no question that digital media are a concern across the disciplines. Jobs in "new media," "digital media," "information studies," "computer-mediated communication," and a host of other locutions are advertised each year in a wide range of fields. There are research centers that put on conferences, funding agencies have expressed an interest in digital media research of several kinds, chairs have been endowed, and annual conferences and scholarly associations have been founded. Digital media studies today encompasses a wide variety of approaches and disciplines. Is disciplinization in its future, and if so, should we view such a development with the skepticism Nelson and Gaonkar apply to Davis's senior colleagues?

The call for this issue asks where digital media studies stands with respect to other disciplines and interdisciplines. Is it an emergent discipline? Should it be? In the remainder of this essay, I address those questions sequentially from the perspective of that subset of cultural studies scholarship which concerns itself with the question of disciplinarity. Following Messer-Davidow, Shumway, and Sylvan (1993), I take disciplinarity to be

\footnotetext{
about the coherence of a set of otherwise disparate elements: objects of study, methods of analysis, scholars, students, journals, and grants, to name a few. To borrow from Foucault, we could say that disciplinarity is the means by which ensembles of diverse parts are brought into particular types of knowledge relations with each other. (Messer-Davidow et al., 1993, p. 3)
}

There are several important aspects of this definition. The first is its heterogeneity. A discipline is composed of elements that have no natural relationship with one another-those relationships are created. This means that a particular method is not inherently appropriate to an ob- ject, but rather that object and method are connected in the practices of the discipline. Second, a discipline encompasses intellectual, institutional, and political dimensions. Disciplines are not neutral, and in analyzing them we must consider their relations to other disciplines, to their purported objects, and their internal relations as well. Third, disciplines have "intentional" and "unintentional" elements. That is, while people must work to put a discipline in place (especially in terms of the fight for resources in the university), there is also a certain degree to which disciplines "happen" as the result of the intersection of a variety of forces, rather than simply being the result of willful action on the part of interested players. Fourth, disciplines are not that different from interdisciplinary fields, except insofar as the "knowledge relations" attain a certain level of institutional consecration.

In fact, disciplines tend to develop out of interdisciplinary fields - so it is eminently appropriate that we pose the question of disciplinarity in digital media studies. Tony Bennett writes, "It is true of many systems of thoughtand especially so of the disciplines which now comprise the humanities - that they begin their career by creating some elbow room for themselves within the interstices of the existing array of disciplinary knowledges" (1997, p. 41). Bennett doesn't specify which fields he means, though it is safe to say that literary studies in the 19th century and psychology in the 20th century follow this pattern. He makes his point in order to argue for disciplinization of cultural studies as a field. But his point also suggests that we can't assume that a discipline is a natural outcome of the development of an interdisciplinary field, since some movements like women's studies did not become disciplines. In fact, many of the new fields that emerged in the 20th century, especially after World War II, have never been universally recognized as disciplines: the various area studies programs, women's studies, black studies, film studies, media studies, cultural studies. This alone would suggest that disciplinization is an unlikely path for digital media studies; to be fair, the "studies" part of the name is a coinage for the purposes of this essay, and not a universally acknowledged descriptor for the field.

To develop this thread as it pertains to digital media studies, I make use of two somewhat different inflections of this approach to disciplinarity, one loosely based on the writings of Michel Foucault and one more closely borrowed from Pierre Bourdieu. My goal is thus not to offer a coherent theory of disciplinarity or to settle debates in that field of study, but rather to use bits of available theories to untangle some of the implications of our responsibility as intellectuals interested in digital media as they pertain to our institutional life in universities and colleges.

Whenever "cultural studies" and "disciplinarity" appear in the same sentence it is easy to expect an antagonism: John Hartley has noted that cultural studies scholars are 
notoriously squeamish about "orthodoxy, manifested positively in a commitment to interdisciplinarity, and negatively in the avoidance of authority" (1991, p. 7). Though there is much to criticize in the current form of disciplinary knowledge in the university, it is something of a fantasy to imagine that we can live above or outside it, and it is pretense to believe that there are no benefits to the disciplinary organization of knowledge. At the same time, I believe it is important to ask whether the best future for digital media studies is in disciplinary form.

The biggest questions regarding the disciplinization of digital media studies must be intellectual. That is, after all, why we do it. If we consider digital media studies as an intellectual enterprise, then I believe it entirely fair to say that the field is not moving toward disciplinarity. I'll state it forcefully: As Gertrude Stein said of Oakland, California, so it is for digital media studies. There is "no there there." The field doesn't know where it fits within the pantheon of humanities and social sciences. To wit: There are canons of digital media research, but no proper or coherent subfields. An informal survey of syllabi around the world via Google or via the Resource Center for Cyberculture Studies will confirm that some texts have already been canonized, but that canonization is roughly split along humanities/social science lines. Other differences rotate around inclusion and exclusion. How does one organize or hierarchize the various different things that fall under the rubric of "digital media": the Internet, DVDs, video games, computer-mediated-communication, digital special effects, computer art, and so forth? One might be inclined to read this as evidence of a canon debate within an already coherent field. Alternatively, one could argue that lots of disciplines contain subfields that don't talk to one another all that much. Geography departments often house cultural critics, physical scientists, historians, and urban planners under one roof. We could tell similar stories about anthropology, psychology, and many other fields. We could go further and show that even within subfields, expertise is further fragmented. To use another example from literary studies, James Sosnoski argues in a very clever essay on the role of examinations that no single person within the field of literary criticism could pass a test on all of its subfields. In a sense, if you were to create a "test" to determine whether the leading lights of literary criticism were capable of practicing the craft, most if not all would fail (1993). Sosnoski's point is that disciplines are to some degree maintained by the discourse of wholeness that actually works in concert with on-the-ground practices of fragmentation and exclusion. ${ }^{3}$

All this is true, and yet disciplines all have their master terms, a certain gel that holds them together. The whole is greater than the sum of its parts. Psychology has "the mind"; literature has "the text" ; anthropology has "culture"; sociology has "society"; geography, archi- tecture, physics and astronomy all have different iterations of "space"; biology has "life"; economics has "the economy." This is one key dimension of disciplinarity: Through a set of "knowledge relations," a discipline interacts with the world to cordon off and in some important sense create its object. Of the human sciences in the 18th century, Foucault wrote that they "did not inherit a certain domain, already outlined, perhaps surveyed as a whole, but allowed to lie fallow, which it was their task to elaborate with positive methods and with concepts that had at least become scientific" (Foucault, 1970, p. 344). Rather, their innovation was to constitute a new object, "man" (the gendered usage seems appropriate given the period), which could then be studied, classified, and organized through the new scholarly methods. This is not one of those "everything is socially constructed" arguments; to take the most obvious example, there was life before biological science. Biology constructs the object "life" as a particular set of problems and operations, which it can then itself operate. What falls outside that domain of "life" falls outside the domain of biology. By virtue of its privileged institutional position, the discipline then claims the right to then substitute the object "life"-inasmuch as anyone claims knowledge of it-for the vast blooming, buzzing confusion (to borrow from William James) that makes up the so-called real world of living. This is even clearer in terms of a concept like "the economy" that brings together many disparate elements under a single rubric. A total, cohesive thing called an "economy" grew not from the rhythms of commerce but from the emergent discourse of economics itself (Gibson-Graham, 1996, pp. 92-119). That said, disciplines never fully constitute their objects; they fight over them. Anthropologists fight over the meaning of culture (e.g., Dominguez, 1996), geographers fight over the meaning of space (e.g., Gregory 1994), and so on. It is these fights within disciplines that maintain their intellectual vibrancy - a dispute or paradigm shift concerning a master term is a major disciplinary event.

For digital media studies, this is an important matter. It would be foolhardy to assert that digital media scholars have simply discovered an already constituted object that we can now easily elaborate, or that the characteristics of our field, the questions we ask, somehow arise "naturally" from our objects of study. Moreover, digital media studies has not, as a field, constituted a new object or defined a new ensemble of objects and methods in the terms that would make it a discipline. Where Messer-Davidow, Shumway, and Sylvan look for a certain cohesiveness, there is instead a certain looseness that characterizes digital media studies. Presently, we are more likely to apply the methods and theories of other fields to our objects than to make a unique contribution to the humanities and social sciences. I am optimistic about our potential to make major contributions, but we aren't yet quite there. It seems that so far the major 
contribution of digital media studies is that we study digital media. While this is a good and necessary development, it is not enough. To say that we have (partially) legitimated a new set of objects of study - digital media - in several disciplines is not the same thing as to say that we have constituted cohesive objects on the same order as other disciplines. This is not necessarily cause for concern, but it does mean that digital media studies has not yet, in any meaningful sense, "happened" as a discipline.

Of greater concern is the fact that a great deal of digital media scholarship has reinvented the wheel when it comes to the history of media, the study of technology, and the history social and cultural thought. Back in 1998, when I did my first survey of the field, I was struck by the degree to which scholars in digital media studies played on the ignorance of their colleagues when it came to digital media (Sterne, 1999). The converse was also true: One can find a litany of books and articles from the 1990s that made outrageous claims about the historical significance of digital media technologies (the most famous is probably Negroponte, 1995). They were able to do so because the authors and the reviewers apparently knew nothing of or did not care about the history of media technologies. This is not to argue that "nothing new" has happened with digital media-only that to know exactly what is new, it would be imperative to know what is old. Although a few histories of digital media are now being published and creeping onto syllabi (e.g., Gitelman, 2003; Abbate, 2000; Schiller, 1999; Edwards, 1996; Ceruzzi, 2003; Bolter \& Grusin, 2000), the field still too often takes its historical cues from official narratives in the industry. Of course we need to study the industry. In some ways we are at a great advantage because we can look at corporate memos and official communiqués. But we can't let the industry tell us what is important to study, how to study digital media, or what our key questions should be. This may seem like an ideological matter, worthy of yet another critique of technophilic celebration of new toys. Indeed, that position is now well represented among digital media scholars. Of course, disciplinization should not simply emerge by reproducing the intellectual currents of the industrial field within the university; disciplinarity requires the coalescence of new objects and methods. But my point goes beyond a critique of industrial ideology, to a broader critique of the ideology of the "new" in academic discourse as well, an ideology that has had a major impact on the way digital media scholars construct their objects of study. Scholars in fields like literature, film, art history, and music have all concluded that it is impossible to coalesce a field around a single medium. But "Internet studies" is a hopelessly backward-looking construct. Why a priori separate the Internet from video games, digital audio, virtual reality, digital developments in cinema and television, and the implantation of microprocessors in a plethora of consumer technologies from cars to clocks to telephones? Why separate the Internet from computer studies, when the latter includes computers not hooked up to the Internet? Most importantly, given the vast and diverse range of traditions of technology study in the university, why a priori separate digital "media" from other technologies?

Our available conceptions of digital media and ICTs need to be expanded. For instance, few scholars of digital media have a working technical, historical, or cultural knowledge of digital audio. As Steve Jones pointed out over a decade ago, many of the key dimensions of "the virtual" were invented in the auditory realm long before any goggles-and-glove version of virtual reality (Jones, 1993). We also have nothing to say about a wide range of mundane digital technologies, from computers in cars to digital clocks. While that might seem silly on one hand, we should remember that Lewis Mumford (1934) put the clock at the center of the modern technological complex because of its ability to organize and rationalize activity. Social importance cannot simply equate with the importance people attribute to things in surveys or interviews; technologies may mean one thing and do another.

This is why we ought to question the assumed separation between digital media and other everyday technologies that we do not normally consider as "communication" or "information" technologies. Both Alice Crawford and James Hay have, with a bit of wit, connected "new media studies" with "refrigerator studies" (Crawford, 2003; Hay, $2000,2001)$. Their point is well taken: We are likely to privilege the computer over the refrigerator as a domestic technology, and yet refrigeration and the technologies that are connected with it (including, as Crawford points out, the Internet itself) are an essential part of domestic routines (see, e.g., Cowan, 1983). Crawford clearly shows the connection between a new appliance like the "Internet fridge" and the politics of women's domestic labor. By assuming, as some digital media scholars have, that "we" have more serious relationships with our computers than our refrigerators, a whole set of gendered and classed assumptions get imported under the guise of scientific common sense. Similarly, Hay writes that communication scholars tend to argue that communication technologies matter because of their function as communication technologies, when in fact other factors, such as their roles in the complex webs of domestic power and practice, may tell us much more about how and why they matter. Criticizing Mark Levy (1989), who in an annoyed response to a hostile reviewer entitled the first chapter of his book on VCRs "VCRs Aren't PopUp Toasters," Hay asks the obvious and overdue question Why do scholars of media assume that toasters or WaterPiks are irrelevant to their research (Hay, 2000, p. 72)? By assuming that the most important technologies are the ones we call media, we denigrate — rather than investigate - the 
implication of digital media in broader networks of technologies, routines, and practices.

My point is not to defend the nobility of kitchen appliances from insults heaped on them by academics, but rather to reassert the need for us to understand technologies as part of heterogeneous networks that do not adhere to the analytical categories we invent for the purposes of scholarship. Technologies have to be understood amid other apparently different, technologies, practices, ideas, and institutions. If we follow the connections, if we look to morphology instead of common sense assertions, we may well begin to tell very different stories about technologies. Writers in science and technology studies (STS) have made this point clear for well over 20 years (e.g., Pinch \& Bijker, 1984; Latour, 1996; Collins \& Pinch, 1998), and writers in the cultural studies tradition have also attended to the impossibility of studying a technology "in itself" or on its own, separate from other technologies and practices (e.g., Slack, 1984; Wise, 1997; Slack \& Fejes, 1987). Thus, it is important to question not only the conceptual robustness of an "Internet studies," but also the possibility of a "digital media studies" insofar as these fields assume their objects matter because they are communication technologies, as opposed to other kinds of technologies. Our challenge is to break with common sense and to ask fundamental questions of all dimensions of the digital world, including aspects of that world that may not, at first blush, seem digital at all (on "the epistemic break," see Bourdieu et al., 1991; on object construction, see Bourdieu \& Wacquant, 1993; on concepts, see Deleuze \& Guattari, 1994). It is not enough to cast digital media as objects; our challenge is to learn better to think with them.

Any serious discussion of disciplinarity should be grounded in the intellectual problems of the field, some of which I have sketched in this essay. To be fair, there are also strategic issues, especially around questions of academic power and reproduction. If digital media studies and its attendant concerns are nothing more than subspecialties in other, "home" disciplines, digital media scholars may eventually and rightfully cry out for relief. After all, as Bourdieu has shown, academic power is ultimately grounded in the power over other individuals - the number of students a scholar produces, the ability to control the speed or slowness with which others' careers advance (1988, pp. 91-93). This may appear cynical when spelled out on the printed page, but it is definitely part of the logic of academic practice across the disciplines. Ambitious academics frequently seek greener pastures where they may have more control over what they teach, more opportunity to supervise graduate students in their areas, and more chances to advance their own work. Tenure and promotion decisions also depend heavily on the legitimation of objects and venues.
Scholars in digital media studies have a wide range of conferences and publishing outlets at their disposal. However, and this is where the strategic question comes in, the symbolic value of those outlets is not guaranteed in other "home" disciplines. In U.S. communication studies (itself a field that is not quite a discipline), for instance, some departments will attach more symbolic value to journals run by the National or International Communication Associations, which have uneven records of supporting scholarship on digital media. Other departments are more open to allowing junior scholars to define their "fields" and are perfectly happy to consider a publication in New Media and Society or The Information Society as a major work of scholarship for the tenure dossier. Similar stories could be told for English literature, psychology, or sociology, to be sure, and these have real impacts on scholars' abilities to produce the kinds of work they want. The good news is that as an increasing number of departments hire specialists in "new media," "digital media," "information technologies," and so forth, they will be forced to recognize the available outlets in the field if they do indeed wish to support research in the area.

As Bourdieu points out in his study of French universities (1988, pp. 12, 36-72), and as most academics are likely to know from personal experience, disciplines may shield scholars from conflicts between fields, but they enmesh scholars in conflicts that happen within fields. The questions of journal publication, proper presses, and so forth would not necessarily go away were there departments of digital media studies. Rather, "disciplinizing" (were it possible to undertake disciplinarity as a purely willful activity) would relieve digital media scholars from the tangled conflicts among the disciplines, only to enmesh them in their own conflicts within the discipline. Differences of focus within departments and the relative power of subdisciplines at a given institution can also affect credentialing, hiring, and tenure. Consider that for tenure in a music department, a dossier would likely be evaluated by composers, historical musicologists, anthropologists of music, musicians, and possibly engineers or archivists. In a geography department, a dossier could be evaluated by urban planners, physical scientists, historical geographers, and cultural theorists. Though these areas are considered disciplines, junior scholars could not reasonably hope that their work would be evaluated only by people who understand their objects and approaches. Though digital media scholars may long for acceptance and a supportive community, it is clear that disciplinization is not a guarantee of security, especially given the cleavages in the field as it presently stands.

For instance, a look at digital media conferences and journals also shows that it is not even clear whether digital media studies is going to happen primarily in the 
domain of the humanities, the social sciences, both, or somewhere inbetween. Currently, social science scholars tend to extend the methods and approaches of their home fields onto digital media as new objects. They assume that digital media are a natural extension of social scientific inquiry. Humanities scholars tend to do the same for humanistic approaches. But humanities and social science fields have different organizing and justificatory logics. Steve Fuller (1993) argues that disciplines justify themselves in part through appeals to worldly knowledge and power-when it is possible for them to do so. This was the basis for the claim to efficacy of humanistic inquiry from the Renaissance through the 19th century, and it is the basis for the contemporary claims of science as a preeminent mode of knowing: its predictive power, its ability to enable the knower to predict and cause events in the world. The humanities, meanwhile, have shifted from a position of legitimating cultural authority to interpreting cultural practice (pp. 130-131; Bauman, 1992, has also made this point). In between lie the social sciences, which use exemplars to "synecdochally represent the working of the entire [discipline]" (Fuller, 1993, p. 129). They aspire to scientific status, but their claims on scientificity are not as rhetorically powerful as those of the so-called "hard" sciences (Fuller is quite clear that he also believes the "hard" sciences also only claim scientificity through rhetorical maneuvers). Bourdieu (1988, p. 122) also argues that the traditional humanities (and some sciences) tend more toward "pure" research than the social sciences, which is more often justified in terms of its "impurity" or applicability. ${ }^{5}$ My point is not that differences of orientation between humanistic and social scientific work must somehow be "resolved" before digital media studies can become a discipline. On the contrary, it is one of the key axes of contention in the field and there is no reason why it couldn't continue. Instead, the key issue here is that the intellectual justification for disciplinarity, the rhetoric behind it, changes depending on whether the argument is made in humanistic or social scientific terms.

All this is to say that if we consider disciplinization as a strategic matter, it marks a number of legitimate concerns, which on an individual level intensify as the experience and prestige of the individual scholar declines. Thus far, digital media scholars have done an excellent job of institution building in the form of journals and scholarly associations, which provide needed venues for new work. Whether becoming a discipline, insofar as that is a willful act, will ameliorate the concerns is another thing entirely. It is more likely that institutional insecurity is a fundamental condition of living at the lower end of academic hierarchies or experience and prestige. Thus, while individuals or groups will work to ameliorate these conditions for others, disciplinization is ultimately a project that refocuses the problems of academic hierarchy and security.

Digital media scholars - and others who work between disciplines - enjoy resources, prestige, and camaraderie of which Nuel Pharr Davis could have only dreamed. If one of the goals of disciplinization is to ensure that a field can reproduce itself, then digital media scholars have already achieved the goal: Many of us have already taught courses and served on doctoral committees for students in the area. In the end, institutional and intellectual concerns are not so far apart. Good pedagogy and good research will, for the time being, be the best ways to foster the field. Indeed, calls toward disciplinization may too easily collapse the intellectual into the institutional, when it should be the other way around. To develop and nourish a vibrant field, digital media scholars must commit to conceptual breadth and intellectual and historical depth in our work.

Perhaps some of the most important questions of our time are these: What happens as technologies change, and how should we understand these changes? Questions like these cross disciplines and fields, and digital media scholars can and should make unique contributions to this burgeoning field of inquiry. There are many other significant questions to which our work can contribute. Digital media scholars have much to say about breaking down the old interpersonal/mass and speech/writing dichotomies that undergird Western theories of language and communication. We have much to say about what counts as subjectivity, identity, agency, personality, social interaction, and the distinction between "private" and "public." We have much to say about politics, power, economics, and justice. The greatest hope for our field-whatever you want to call it-lies in our ability to address, reframe, or re-ask really big questions that cut across all the human sciences. In the end, disciplinarity is nothing more than an institutional promise for our field. Our work has much more important and much more pressing intellectual and political promises. Our challenge is to fulfill them.

\section{NOTES}

1. Throughout this article I use "we" in a naive fashion. It is meant only as a "hail" to the reader, not to imply an existing, coherent bloc of digital media scholars.

2. It's a devil's choice in naming alternatives at the moment. I chose "digital media studies" over three additional terms because it is broad, descriptive of a common thread across widely varying research programs, and inclusive. "New media studies" implies a value judgment (think about how the word "new" gets used in the context of advertising or scholarship) and a periodization that I want to question. "Cyberculture studies" is nicely inclusive, though the only people I know who self-identify as cyberculture scholars are humanists. More to the point, 
I'm not sure we should assume, definitionally, that digital media create a coherent or separate cultural domain. "ICT studies," meanwhile, seems to be a term largely used by people with a social science or policy orientation. To be fair, "digital media studies" has its problems as well, as Lev Manovich (2001) has clearly detailed, and he's probably right.

One other point to make here is that I mean to define digital media studies as an academic field. By digital media studies I refer to the field and its scholarship as it exists in the university. While there are intellectuals outside the academic system, they are just that - not part of the system of disciplines within the university. Artists, activists, corporate research and development $(\mathrm{R} \& \mathrm{D})$ people, and teenage hackers all have important things to teach scholars, to be sure, but their work and, more importantly, their working conditions are fundamentally different from the work and conditions for scholars.

3. "Exclusion" has come to have an exclusively negative connotation in some scholarly quarters. I don't mean it that way; just as a musician must exclude some notes from the scale to make a good melody, a scholar must exclude some approaches and ideas in order to create meaningful knowledge. That said, I am fully aware that such practices can have social costs if scholars are not self-reflexive about the relationship between their intellectual and institutional lives. I consider that further, later in this article.

4. John Mowitt (1992) has argued that the "text" exceeds the disciplinarity of literary study, but his argument is actually an attack on disciplines as such. One can find analogous arguments in most other fields of the humanities and social sciences. My question here is somewhat different: Given an existing institutional field of disciplines and interdisciplines, what is the best course of action for digital media scholars right now?

5. Like Fuller, Bourdieu sees this less as a value judgment than as an attitudinal or justificatory orientation.

\section{REFERENCES}

Abbate, Janet. 2000. Inventing the Internet. Cambridge, MA: MIT Press.

Bauman, Zygmunt. 1992. Intimations of postmodernity. New York: Routledge.

Bennett, Tony. 1997. Culture: A reformer's science. Thousand Oaks, CA: Sage.

Bolter, Jay, and Grusin, Richard. 2000. Remediation: Understanding new media. Cambridge, MA: MIT Press.

Bourdieu, Pierre. 1988. Homo academicus, trans. P. Collier. New York: Polity Press.

Bourdieu, Pierre, Chamboredon, Jean-Claude, and Passeron, JeanClaude. 1991. The craft of sociology: Epistemological preliminaries, trans. R. Nice. New York: Walter de Gruyter.

Bourdieu, Pierre, and Wacquant, Loic J. D. 1993. An invitation to reflexive sociology. Chicago: University of Chicago Press.

Ceruzzi, Paul. 2003. History of modern computing, 2nd ed. Cambridge, MA: MIT Press.

Collins, Harry, and Pinch, Trevor. 1998. The golem at large: What everyone should know about technology. New York: Cambridge University Press.

Cowan, Ruth Schwartz. 1983. More work for mother: The ironies of household technology from the open hearth to the microwave. New York: Basic Books.
Crawford, Alice. 2003. The city in the future perfect: Information technology, utopianism and urban life. $\mathrm{PhD}$ dissertation, Communication, University of Pittsburgh, Pittsburgh.

Davis, Nuel Pharr. 1968. Lawrence and Oppenheimer. New York: Simon and Schuster.

Deleuze, Gilles, and Guattari, Felix. 1994. What is philosophy?, trans. by H. Tomlinson and G. Burchell. New York: Columbia University Press.

Dominguez, Virginia. 1996. Disciplining anthropology. In Disciplinarity and dissent in cultural studies, eds. C. Nelson and D. P. Gaonkar, pp. 37-61. New York: Routledge.

Edwards, Paul. 1996. The closed world: Computers and the politics of discourse in Cold War America. Cambridge, MA: MIT Press.

Foucault, Michel. 1970. The order of things: An archaeology of the human sciences. New York: Vintage Books.

Fuller, Steve. 1993. Disciplinary boundaries and the rhetoric of the social sciences. In Knowledges: Historical and critical studies in disciplinarity, eds. E. Messer-Davidow, D. Shumway, and D. Sylvan, pp. 125-149. Charlottesville: University of Virginia Press.

Gibson-Graham, J. K. 1996. The end of capitalism (as we knew it). Cambridge, MA: Blackwell.

Gitelman, Lisa, ed. 2003. New media 1740-1915. Cambridge, MA: MIT Press.

Gregory, Derek. 1994. Geographical imaginations. Cambridge, MA: Blackwell.

Hartley, John. 1991. Popular reality: A (hair) brush with cultural studies. Continuum 4(2):5-18.

Hay, James. 2000. Unaided virtues: The (neo-)liberalization of the domestic sphere. Television and New Media 1(1):53-73.

Hay, James. 2001. Locating the televisual. Television and New Media 2(3):205-234.

Jones, Steve. 1993. A sense of space: Virtual reality, authenticity and the aural. Critical Studies in Mass Communication 10:238252.

Latour, Bruno. 1996. Aramis, or the love of technology. Cambridge, MA: Harvard University Press.

Levy, Mark. 1989. The VCR age. Newbury Park, CA: Sage.

Manovich, Lev. 2001. The language of new media. Cambridge, MA: MIT Press.

Messer-Davidow, Ellen, Shumway, David, and Sylvan, David. 1993. Disciplinary ways of knowing. In Knowledges: Historical and critical studies in disciplinarity, eds. E. Messer-Davidow, D. Shumway, and D. Sylvan, pp. 1-21. Charlottesville: University of Virginia Press.

Mowitt, John. 1992. Text: The genealogy of an antidisciplinary object. Durham, NC: Duke University Press.

Mumford, Lewis. 1934. Technics and civilization. New York: Harcourt, Brace.

Negroponte, Nicholas. 1995. Being digital. New York: Knopf.

Nelson, Cary, and Gaonkar, Dilip Parameshwar. 1996. Cultural studies and the politics of disciplinarity: An introduction. In Disciplinarity and dissent in cultural studies, eds. C. Nelson and D. P. Gaonkar, pp. 1-19. New York: Routledge.

Pinch, Trevor, and Bijker, Wiebe. 1984. The social construction of facts and artefacts: Or how the sociology of science and the sociology of technology might benefit each other. Social Studies of Science 14:399-441. 
Schiller, Dan. 1999. Digital capitalism: Networking the global market system. Cambridge, MA: MIT Press.

Slack, Jennifer Daryl. 1984. Communication technologies and society: Conceptions of causality and the politics of technological intervention. Norwood, NJ: Ablex.

Slack, Jennifer Daryl, and Fejes, Fred, eds. 1987. Ideologies of the information age. Norwood: Ablex.

Sosnoski, James. 1993. Examining exams. In Knowledges: Historical and critical studies in disciplinarity, eds. E. Messer-Davidow,
D. Shumway, and D. Sylvan. Charlottesville: University of Virginia Press.

Sterne, Jonathan. 1999. Thinking the Internet: Cultural studies vs. the Millennium. In Doing internet research, ed. S. Jones. Thousand Oaks, CA: Sage.

Vico, Giambattista. 1984. The new science of Giambattista Vico, trans. T. Bergin and M. Fisch. Ithaca, NY: Cornell University Press.

Wise, J. MacGregor. 1997. Exploring technology and social space. Thousand Oaks, CA: Sage. 
Copyright of Information Society is the property of Taylor \& Francis Ltd. The copyright in an individual article may be maintained by the author in certain cases. Content may not be copied or emailed to multiple sites or posted to a listserv without the copyright holder's express written permission. However, users may print, download, or email articles for individual use. 